\title{
Combination of Scanning Probe Microscopy and Coordination Chemistry: Structural and Electronic Study of Bis(methylbenzimidazolyl)ketone and Its Iron Complex
}

\author{
Emma Folkertsma, ${ }^{\dagger}$ Joost van der Lit, ${ }^{\ddagger}$ Francesca Di Cicco, ${ }^{\ddagger}$ Martin Lutz, ${ }^{\S}$ Robertus J. M. Klein Gebbink, ${ }^{\dagger}$
} Ingmar Swart, ** and Marc-Etienne Moret* ${ }^{* \dagger}$

†Organic Chemistry \& Catalysis, Debye Institute for Nanomaterials Science, Utrecht University, Universiteitsweg 99, 3584 CG Utrecht, The Netherlands

${ }^{\ddagger}$ Condensed Matter and Interfaces, Debye Institute for Nanomaterials Science, Utrecht University, P.O. Box 80000, 3508 TA Utrecht, The Netherlands

${ }^{\S}$ Crystal and Structural Chemistry, Bijvoet Center for Biomolecular Research, Faculty of Science, Utrecht University, Padualaan 8 , $3584 \mathrm{CH}$ Utrecht, The Netherlands

Supporting Information

\begin{abstract}
Here, we report the bulk synthesis of $\left[\mathrm{Fe}^{\mathrm{II}}(\mathrm{BMBIK}) \mathrm{Cl}_{2}\right]$ bearing the redox noninnocent bis(methylbenzimidazolyl)ketone (BMBIK) ligand and the synthesis of the similar complex $\left[\mathrm{Fe}^{\mathrm{I}}(\mathrm{BMBIK})\right]^{+}$on a $\mathrm{Au}(111)$ surface using lateral manipulation at the atomic level. Cyclic voltammetry and scanning tunneling spectroscopy are shown to be useful techniques to compare the coordination compound in solution with the one on the surface. The total charge, as well as the oxidation and spin state of
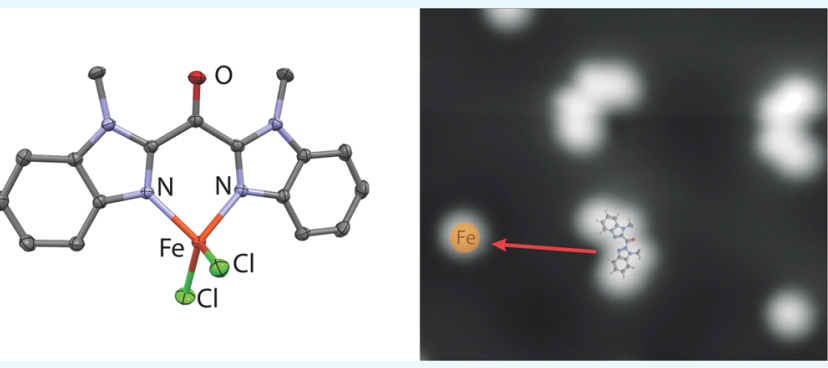
$\left[\mathrm{Fe}^{\mathrm{I}}(\mathrm{BMBIK})\right]^{+}$, are investigated by comparison of the shape of the lowest unoccupied molecular orbital (LUMO), visualized by tunneling through the LUMO, with theoretical models. The similar reduction potentials found for the solution and surface compounds indicate that the major effect of lowering the LUMO upon coordination of $\mathrm{BMBIK}$ to the iron center is conserved on the surface. The synthesis and analysis of $\left[\mathrm{Fe}^{\mathrm{I}}(\mathrm{BMBIK})\right]^{+}$using scanning tunneling microscopy, scanning tunneling spectroscopy, and atomic force microscopy are the first steps toward mechanistic studies of homogeneous catalysts with redox noninnocent ligands at the single molecule level.
\end{abstract}

\section{INTRODUCTION}

The use of redox noninnocent ligands (NILs) in homogeneous catalysis has been studied extensively in the past few decades. $^{1-6}$ The key feature of redox active NILs is their ability to store and release electrons during catalysis, facilitating two-electron elementary steps on first-row transition metal complexes. $^{3,7-9}$ This expands the scope of reactions that can be catalyzed using affordable and nontoxic first-row transition metals. ${ }^{10-13}$ Some examples of NILs with great potential are bis(imino)pyridines, ${ }^{8,14}$ bis(amidophenolates), ${ }^{15}$ bis(amidophenyl)amides, ${ }^{16,17}$ formazanates, ${ }^{18}$ and catecholates. ${ }^{19}$ Analytical and theoretical studies by Chirik et al. have allowed the assignment of the oxidation and spin state of the metal centers in complexes bearing a bis(imino)pyridine ligand and have led to a proposed mechanism for catalytic olefin hydrogenation using such $\mathrm{Fe}$ complexes as catalysts. ${ }^{8,20}$ They proposed a lowcoordinate iron(II) complex with a doubly reduced bis(imino)pyridine diradical to be the catalytically active species. Oxidative addition of $\mathrm{H}_{2}$ and reductive elimination of the product are essential steps in the catalytic cycle, and both involve the mobilization of ligand-centered electrons. Meanwhile, the iron(II) oxidation state is preserved. One of the major questions in mechanistic studies on complexes bearing NILs concerns the oxidation state of the metal center, which is generally not trivial to determine for this type of complex. Moreover, the detection of reactive intermediates involved in the catalytic cycle is often highly challenging, limiting insight into the catalytic mechanism.

One way these challenges might be overcome is by using scanning probe microscopy (SPM) techniques to study single molecules. SPM at low temperatures $(T=5 \mathrm{~K})$ allows isolated molecules to be studied. Furthermore, lateral manipulation of molecules or single atoms provides control over step-by-step reactions. Additionally, using scanning tunneling spectroscopy (STS), the energy, as well as the spatial extent of the frontier molecular orbitals can be measured. ${ }^{21,22}$ These quantities can be compared to those from density functional theory (DFT) calculations. This provides detailed information on the electronic structure of the studied molecules.

Received: December 15, 2016

Accepted: March 23, 2017

Published: April 10, 2017 


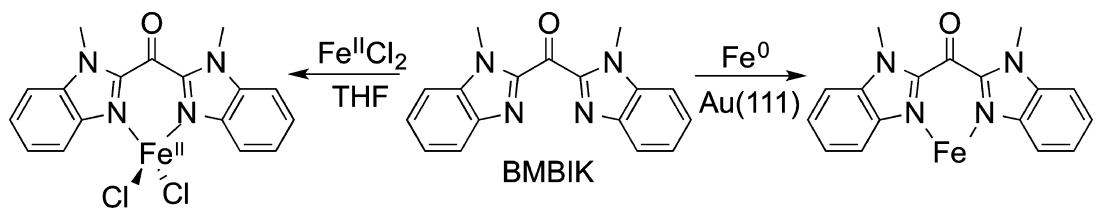

Figure 1. Compounds and reactions under study, in solution (left) and on the surface (right).

Lateral manipulation of molecules in scanning tunneling microscopy (STM) has been used for the on-surface step-bystep synthesis of coordination compounds. ${ }^{23-29}$ However, the study of the same molecules in the bulk phase and the comparison of their bulk properties to their properties on the surface are more rare. ${ }^{30-32}$ For example, Wang et al. studied titanyl phthalocyanine on a highly oriented pyrolytic graphite surface and in dichlorobenzene solution to investigate the influence of gasses on the electronic structure. They used cyclic voltammetry (CV) and STS to compare the solution and surface compounds, and found good consistency between the STS and the CV data.

STM has also been used to study catalysts. In those cases, typically but not exclusively well-defined single crystals are used as a model for the catalyst. ${ }^{33-40}$ Additionally, catalytically active coordination compounds have been investigated in action. For example, STM experiments on $\mathrm{Mn}$-porphyrin epoxidation catalysts provided insight into the mechanism of the reaction and, amongst other things, showed the distribution of the oxygen atoms of $\mathrm{O}_{2}$ over two adjacent catalyst molecules at the surface. $^{26,41}$

In this study, the formation and electronic structure of a catalyst model compound are investigated by combining the bulk synthesis of a coordination compound, single molecule scanning probe microscopy at $4.5 \mathrm{~K}$, and theoretical studies. The Fe-BMBIK complex (BMBIK: bis(methylbenzimidazolyl)ketone) is selected as a model for catalysts because previous studies on the related compound bis(1-methyl-4,5diphenylimidazolyl)ketone $\left(\mathrm{BM}^{\mathrm{diPh}} \mathrm{IK}\right)$ have shown its ability to store electrons, making its $\mathrm{Fe}$ complexes good models for catalysts supported by redox NILs. ${ }^{42}$ Additionally, the conjugated $\pi$-system of the BMBIK ligand is both flat and rigid, which are useful properties for surface studies (Figure 1). The study of coordination compounds on the surface might allow the detection of (low-coordinate) reactive catalytic intermediates that cannot be detected in solution. ${ }^{43}$

Similar to Wang et al., CV data acquired in solution are compared to that of STS data. Using these two techniques, the changes in the electronic structure of the BMBIK ligand upon coordination to the metal center were studied. By comparing the measured and calculated shape of the lowest unoccupied molecular orbital (LUMO) of the complex, the oxidation state of $\mathrm{Fe}$ in $[\mathrm{Fe}(\mathrm{BMBIK})]$ on the surface could be assigned. Finally, reactive low-coordinate iron species, relevant to proposed catalytic intermediates, are studied on the single molecule level.

\section{RESULTS}

Complex Synthesis. The BMBIK ligand was synthesized starting from commercially available benzimidazole, according to a literature procedure. ${ }^{44}$ The iron complex $\left[\mathrm{Fe}(\mathrm{BMBIK}) \mathrm{Cl}_{2}\right]$ was obtained as a green precipitate from the reaction of BMBIK with $\mathrm{FeCl}_{2} \cdot 1.5 \mathrm{THF}$ in tetrahydrofuran (THF) at room temperature. The formation of this complex was confirmed with ${ }^{1} \mathrm{H} \mathrm{NMR}$, IR, UV-vis spectroscopy, high-resolution electrospray ionization mass spectrometry (ESIMS), CV, and elemental analysis. The ${ }^{1} \mathrm{H}$ NMR spectrum shows five paramagnetically shifted signals ranging from -40 to 40.4 $\mathrm{ppm}$ indicating the formation of a symmetrical high-spin complex. The structure of $\left[\mathrm{Fe}(\mathrm{BMBIK}) \mathrm{Cl}_{2}\right]$ was determined by $\mathrm{X}$-ray crystallography; the molecular structure and selected bond lengths and angles are included in Figure 2 and Table 1.

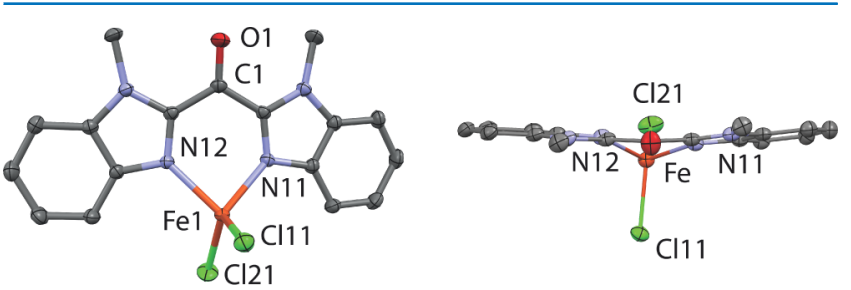

Figure 2. Side and top view of the molecular structure of $\left[\mathrm{Fe}(\mathrm{BMBIK}) \mathrm{Cl}_{2}\right]$. Hydrogen atoms and a second independent complex molecule have been omitted for clarity and displacement ellipsoids are drawn at the $50 \%$ probability level.

Table 1. Selected Bond Lengths and Angles for Both Independent Molecules of $\left[\mathrm{Fe}(\mathrm{BMBIK}) \mathrm{Cl}_{2}\right]$

\begin{tabular}{|c|c|c|}
\hline & $\begin{array}{l}\text { bond length }(\AA) n=1 \text {, } \\
\qquad m=2\end{array}$ & $\begin{array}{l}\text { bond length }(\AA) n=3, \\
m=4\end{array}$ \\
\hline $\mathrm{Fe}-\mathrm{Cl} 1 \mathrm{n}$ & $2.2454(4)$ & $2.2513(4)$ \\
\hline $\mathrm{Fe}-\mathrm{Cl} 2 \mathrm{n}$ & $2.2335(4)$ & $2.2310(4)$ \\
\hline $\mathrm{Fe}-\mathrm{N} 1 \mathrm{n}$ & $2.0751(11)$ & $2.0657(12)$ \\
\hline $\mathrm{Fe}-\mathrm{N} 1 \mathrm{~m}$ & $2.0738(11)$ & $2.0779(12)$ \\
\hline $\mathrm{N} 1 \mathrm{n}-\mathrm{C} 2 \mathrm{n}$ & $1.3353(17)$ & $1.3382(17)$ \\
\hline $\mathrm{N} 1 \mathrm{~m}-\mathrm{C} 2 \mathrm{~m}$ & $1.3360(16)$ & $1.3379(17)$ \\
\hline \multirow[t]{2}{*}{$\mathrm{C}(\mathrm{n})-\mathrm{O}(\mathrm{n})$} & $1.2177(16)$ & $1.2199(17)$ \\
\hline & angle $(\operatorname{deg}) n=1, m=2$ & angle (deg) $n=3, m=4$ \\
\hline $\mathrm{N} 1 \mathrm{n}-\mathrm{Fe}-\mathrm{N} 1 \mathrm{~m}$ & $86.25(4)$ & $86.65(5)$ \\
\hline $\mathrm{Cl} 1 \mathrm{n}-\mathrm{Fe}-\mathrm{Cl} 2 \mathrm{n}$ & $115.316(16)$ & $117.741(16)$ \\
\hline $\mathrm{N} 1 \mathrm{~m}-\mathrm{Fe}-\mathrm{Cl} 2 \mathrm{n}$ & 111.96(3) & $118.56(3)$ \\
\hline $\mathrm{N} 1 \mathrm{n}-\mathrm{Fe}-\mathrm{Cl} 1 \mathrm{n}$ & $108.99(3)$ & $108.09(3)$ \\
\hline $\mathrm{C} 2 \mathrm{n}-\mathrm{N} 1 \mathrm{n}-\mathrm{Fe}$ & $125.77(9)$ & $127.95(10)$ \\
\hline $\mathrm{C} 4 \mathrm{n}-\mathrm{N} 1 \mathrm{n}-\mathrm{Fe}$ & $126.18(9)$ & $125.61(10)$ \\
\hline $\mathrm{C} 4 \mathrm{n}-\mathrm{N} 1 \mathrm{n}-\mathrm{C} 2 \mathrm{n}$ & $105.57(11)$ & $105.92(11)$ \\
\hline $\mathrm{C} 2 \mathrm{~m}-\mathrm{N} 1 \mathrm{~m}-\mathrm{Fe}$ & $126.81(9)$ & $124.91(10)$ \\
\hline $\mathrm{C} 4 \mathrm{~m}-\mathrm{N} 1 \mathrm{~m}-\mathrm{Fe}$ & $124.70(9)$ & $124.36(9)$ \\
\hline $\mathrm{C} 4 \mathrm{~m}-\mathrm{N} 1 \mathrm{~m}-\mathrm{C} 2 \mathrm{~m}$ & $105.84(10)$ & $106.01(11)$ \\
\hline
\end{tabular}

Two independent complex molecules are present in the asymmetric unit; both have a slightly distorted tetrahedral geometry around the iron center. The $\mathrm{Fe}-\mathrm{N}$ bond lengths of $2.0657(12)-2.0779(12) \AA$ are typical for tetrahedral high-spin $\mathrm{Fe}^{\mathrm{II}}$-complexes. ${ }^{45,46}$ From the top view in Figure 2 it can be clearly seen that the BMBIK ligand stays flat upon coordination to the iron center, which makes this complex a good candidate for surface studies.

Investigation of BMBIK and Its Iron Complex on a Au(111) Surface. The synthesis of the target complex $[\mathrm{Fe}(\mathrm{BMBIK})]$ on a surface was achieved by co-evaporation of 

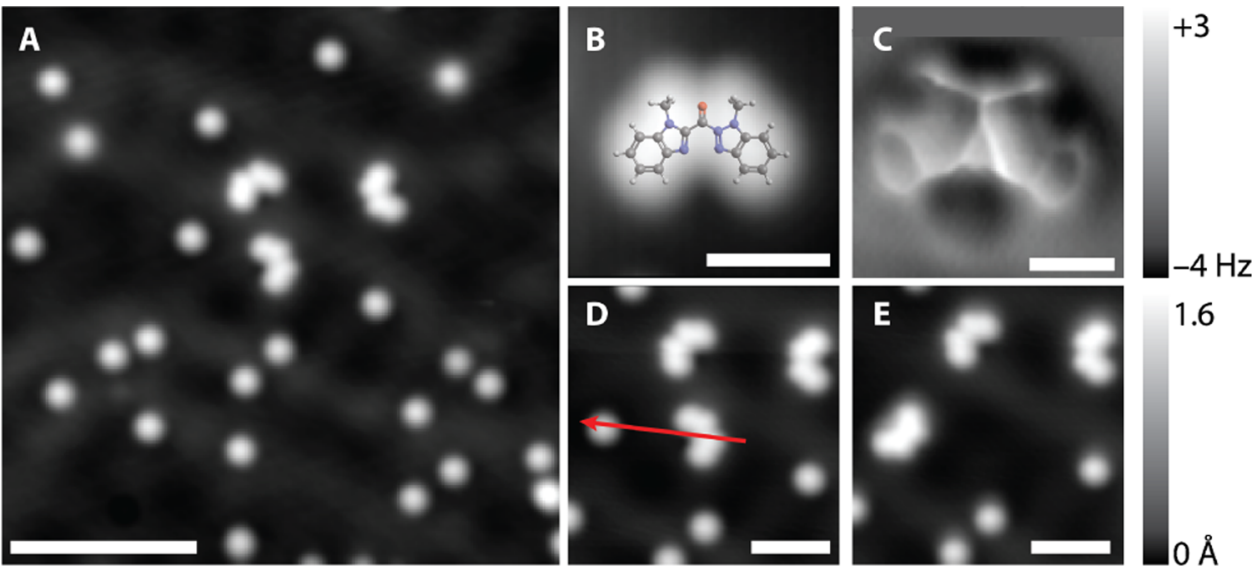

Figure 3. A) STM overview of BMBIK and Fe atoms adsorbed on $\mathrm{Au}(111)$ (0.1 V, $20 \mathrm{pA}$, scale bar: $5 \mathrm{~nm}$ ). (B) STM image of BMBIK with superimposed theoretical model $(0.1 \mathrm{~V}, 10 \mathrm{pA}$, scale bar: $1 \mathrm{~nm})$. (C) Constant height AFM image of BMBIK on Au(111) acquired with a CO terminated tip ( $\Delta z=-0.75 \AA$ w.r.t. STM set-point $0.1 \mathrm{~V}$ and $10 \mathrm{pA}$, scale bar: $0.5 \mathrm{~nm}$ ). (D, E) STM manipulation steps. (D) The red arrow indicates the manipulation trajectory of the ligand toward the Fe atom $(0.1 \mathrm{~V}, 20 \mathrm{pA}$, scale bar: $2 \mathrm{~nm})$. (E) STM image showing the complex formed by manipulation on the left. Manipulation parameters: $\Delta z=-2.5 \AA$, bias $=0 \mathrm{~V}$. $(0.1 \mathrm{~V}, 20 \mathrm{pA}$, scale bar: $2 \mathrm{~nm})$.

iron atoms and the BMBIK ligand using an electron-beam evaporator onto a $\mathrm{Au}(111)$ single crystal held at $4.5 \mathrm{~K}$. The $\mathrm{Au}(111)$ surface, with its characteristic herringbone reconstruction, was chosen because of its weak interactions with molecules, which is a useful property for lateral manipulation experiments and electronic characterization. ${ }^{2,47}$

An STM overview image shows the adsorption of both BMBIK molecules (butterfly shapes), as well as iron atoms (spherical protrusions), on the $\mathrm{Au}(111)$ surface (Figure 3A). The butterfly-shaped protrusions resemble the expected shape and size of the BMBIK ligand (zoomed in image in Figure 3B). The smaller spherical protrusions are individual $\mathrm{Fe}$ atoms. To eliminate any ambiguity in the identification of the molecules, an atomically resolved atomic force microscopy (AFM) image was acquired using a $\mathrm{CO}$ terminated tip (Figure $3 \mathrm{C}$ ), from which characteristic parts of BMBIK, like the benzimidazole rings and the methyl substituents, can clearly be recognized. ${ }^{48}$ The apparent bond between the methyl group and the carbonyl oxygen, as well as the deformed bond lengths, are ascribed to an imaging artifact. ${ }^{49-51}$ Using lateral manipulation, the $[\mathrm{Fe}(\mathrm{BMBIK})]$ complex was formed by moving BMBIK toward an iron atom (Figure 3D, details about the manipulation can be found in the Experimental Section). At the bias used in Figure $3 \mathrm{E}$, the shape of the complex still resembles the shape of a BMBIK molecule, and it is not easily distinguished from the free ligands.

Surface and Solution Electrochemical Properties. To discriminate the complex from the free ligand on the surface, STS spectra were recorded on both the complex and on a free ligand (Figure 4). The large changes in the STS spectra conclusively show that the manipulation resulted in formation of an $[\mathrm{Fe}(\mathrm{BMBIK})]$ complex. Electronic characterization using both STS and CV allows for a comparison of the molecular properties in solution (bulk) and on the surface (locally) for both the free ligand and the iron complex. ${ }^{52}$ It should be kept in mind that the iron-centered tetrahedral complex in solution is in its +2 oxidation state and has two coordinating chlorideligands, whereas the planar complex on the surface consists only of a BMBIK molecule and an iron center (no chloride) of which the oxidation state is not clear a priori.

The results of the electronic characterization of both $\mathrm{CV}$ (top) and STS (bottom) on the free ligand (blue) and the iron



Figure 4. Top: voltammograms of BMBIK (blue) and [Fe(BMBIK)$\mathrm{Cl}_{2}$ ] (green), measured in $0.1 \mathrm{M} \mathrm{Bu}_{4} \mathrm{NPF}_{6}$ in $\mathrm{MeCN}$, referenced vs vacuum measured reductively at a scan rate of $100 \mathrm{mV} / \mathrm{s}$. The voltammograms are normalized to the most intense signal. Bottom: differential conductance spectra of BMBIK (blue) and [Fe(BMBIK)] (green). Both spectra were acquired at center positions.

complex (green) are shown in Figure 4. To compare the energies of the STS and CV data, both are referenced to vacuum rather than to the more commonly used "zeros" of ferrocene and the surface $\mathrm{E}_{\mathrm{F}}$ for CV and STS, respectively. For clarity, these scales are also included in Figure 4.

In $\mathrm{CV}$, both BMBIK and the iron complex show one major redox process in the reductive region. The ligand shows a quasireversible reduction wave with a reduction potential $\left(E_{\mathrm{pc}}\right)$ of $-3.3 \mathrm{~V}$ versus vacuum $\left(E_{\mathrm{pc}}=-1.8 \mathrm{~V}\right.$, half-wave potential $E_{1 / 2}=-1.7 \mathrm{~V}$ vs ferrocene). For the iron complex, a rather irreversible reduction wave is found at $E_{\mathrm{pc}}=-4.0 \mathrm{~V}$ versus vacuum ( $-1.1 \mathrm{~V}$ vs ferrocene) (Figure 4, top). Similar 



Figure 5. Top: bias-dependent STM images of the free ligand and complex, resonantly tunneling through the LUMO of the ligand or complex. $I=$ $20 \mathrm{pA}, V=1.25 \mathrm{~V}$, scale bar: $2 \mathrm{~nm}$. Bottom: line profiles corresponding to the red arrows shown in the top images. The blue lines correspond to the images recorded at $0.1 \mathrm{~V}$, and the green lines correspond to the images recorded at 2.0 and $1.25 \mathrm{~V}$ for the ligand and the complex, respectively. On the $x$ axis, the approximate position of the carbonyl (red and black spheres for $\mathrm{O}$ and $\mathrm{C}$, respectively) and if applicable the iron center (yellow sphere) are indicated.

paramagnetic ${ }^{1} \mathrm{H}$ NMR shifts observed for $\left[\mathrm{Fe}^{\mathrm{II}}(\mathrm{BMBIK}) \mathrm{Cl}_{2}\right]$ in both the weakly coordinating solvent dichloromethane and in acetonitrile (see Figure S2) suggest that the main species in solution does not incorporate additional solvent molecules under the CV conditions. The reduction of the iron complex is proposed to be ligand-centered based on its similarities to the closely related $\left[\mathrm{Fe}^{\mathrm{II}}\left(\mathrm{BM}^{\mathrm{diPh}} \mathrm{IK}\right) \mathrm{Cl}_{2}\right]$ and $\left[\mathrm{Zn}^{\mathrm{II}}\left(\mathrm{BM}^{\mathrm{diPh}} \mathrm{IK}\right) \mathrm{Cl}_{2}\right]$ complexes. ${ }^{42}$ Coordination of the ligand to a Lewis acidic metal center makes the reduction more accessible with a shift in the potential of $\Delta E_{\mathrm{CV}}=0.7 \mathrm{~V}$.

In the STS spectra of the free ligand and the complex, peaks are observed at distinctively different voltages: -3.2 and $-4.2 \mathrm{~V}$ versus vacuum (2.2 and $1.2 \mathrm{~V}$ vs $\mathrm{E}_{\mathrm{F}} \mathrm{Au}(111)$ ) for the ligand and complex, respectively (Figure 4, bottom). No states were found in the experimentally accessible part of the oxidative region. Both spectra could be fitted with a single Gaussian, hence it is likely that a single state is responsible for the observed resonance, or two states that should be very close in energy $(\Delta E<100 \mathrm{meV})$. The difference in the measured potential between the ligand and the complex $\left(\Delta E_{\mathrm{STS}}=1.0 \mathrm{~V}\right)$ clearly shows a shift in energy of the LUMO upon coordination of the ligand to a Lewis acidic metal atom. ${ }^{25,42,53}$ The shift in the energy of the ligand-centered LUMO upon coordination to the iron center on the surface is of the same order of magnitude as the shift observed in solution (Figure 4). Peak shifts due to the potential distribution in the tunnel barrier are on the order of $10 \mathrm{mV}^{54}$

The similarities between the CV and STS data, both in reduction potentials and in the observed shift in potential upon coordination of the BMBIK ligand to the iron center, indicate that the complex on the $\mathrm{Au}(111)$ surface can be compared with the complex in solution. The combination of CV and STS provides the opportunity to compare surface and solution redox processes and illustrates the potential of STM studies as a promising tool to study low-coordinate or reactive coordination compounds on the single molecule level.

Variable Bias Measurements. Constant current STM images were recorded at various voltages to investigate the spatial extent of the resonances discussed in Figure 4. Figure 5A,B shows STM images featuring two ligand molecules when the dominant tunneling pathways are nonresonant and via the LUMO level, respectively. At $2.0 \mathrm{~V}$ (resonant tunneling) the apparent height of the ligands is much larger than that at $0.1 \mathrm{~V}$ (nonresonant tunneling). The shape of the free ligand in this image now resembles the LUMO responsible for the resonance at $2.07 \mathrm{~V}^{22}$

Figure 5C,D shows the iron complex, two ligand molecules, and some free iron atoms. The LUMO of the complex, responsible for the resonance at $1.15 \mathrm{~V}$, was imaged by scanning at a bias of $1.25 \mathrm{~V}$ (Figure 5D). At this voltage, the apparent height of the center of the complex is much larger than that of the free ligands ( 2.0 vs $1.25 \AA)$. At this bias, the complex can easily be distinguished from the ligand molecules, as these are not affected because they have no available orbitals at this potential (compare the appearance of the complex and free ligands in Figure 5D). The shape of the LUMO can now be compared to that from theoretical models, as discussed in the next section.

Additionally, four line profiles are provided in Figure 5E,F. The profiles correspond to the red lines as indicated in Figure $5 \mathrm{~A}, \mathrm{C}$ and go through the carbonyl and the iron center. The blue lines correspond to the images recorded at $0.1 \mathrm{~V}$, and the green lines correspond to the images recorded at 2.0 and $1.25 \mathrm{~V}$ for the ligand and the complex, respectively. The positions of $\mathrm{Fe}, \mathrm{C}$, and $\mathrm{O}$ are indicated with spheres; the distances between the $\mathrm{Fe}, \mathrm{C}$, and $\mathrm{O}$ are based on DFT calculations (+1 charge, high spin); however, the absolute positions along the line profile are only approximate. The profiles in Figure $5 \mathrm{E}$ over the free ligand show an increase of approximately $1 \AA$ when tunneling resonantly through the LUMO. No clear submolecular features could be observed. The line profiles over the complex do show some submolecular features when in resonance with the LUMO. The bimodal line profile indicates resonance enhancement on both the $\mathrm{CO}$ and the Fe side.

Computational Studies. To obtain further insight into the electronic structure of the $[\mathrm{Fe}(\mathrm{BMBIK})]$ complex on the surface and the oxidation state of the iron center, DFT calculations were performed. The charge state of the complex on the $\mathrm{Au}(111)$ surface is determined by the energetic alignment of the frontier molecular orbitals of the complex 
Table 2. DFT Results of the High-Spin $[\mathrm{Fe}(\mathrm{BMBIK})]$ Complexes at Three Charge States ${ }^{a, b}$

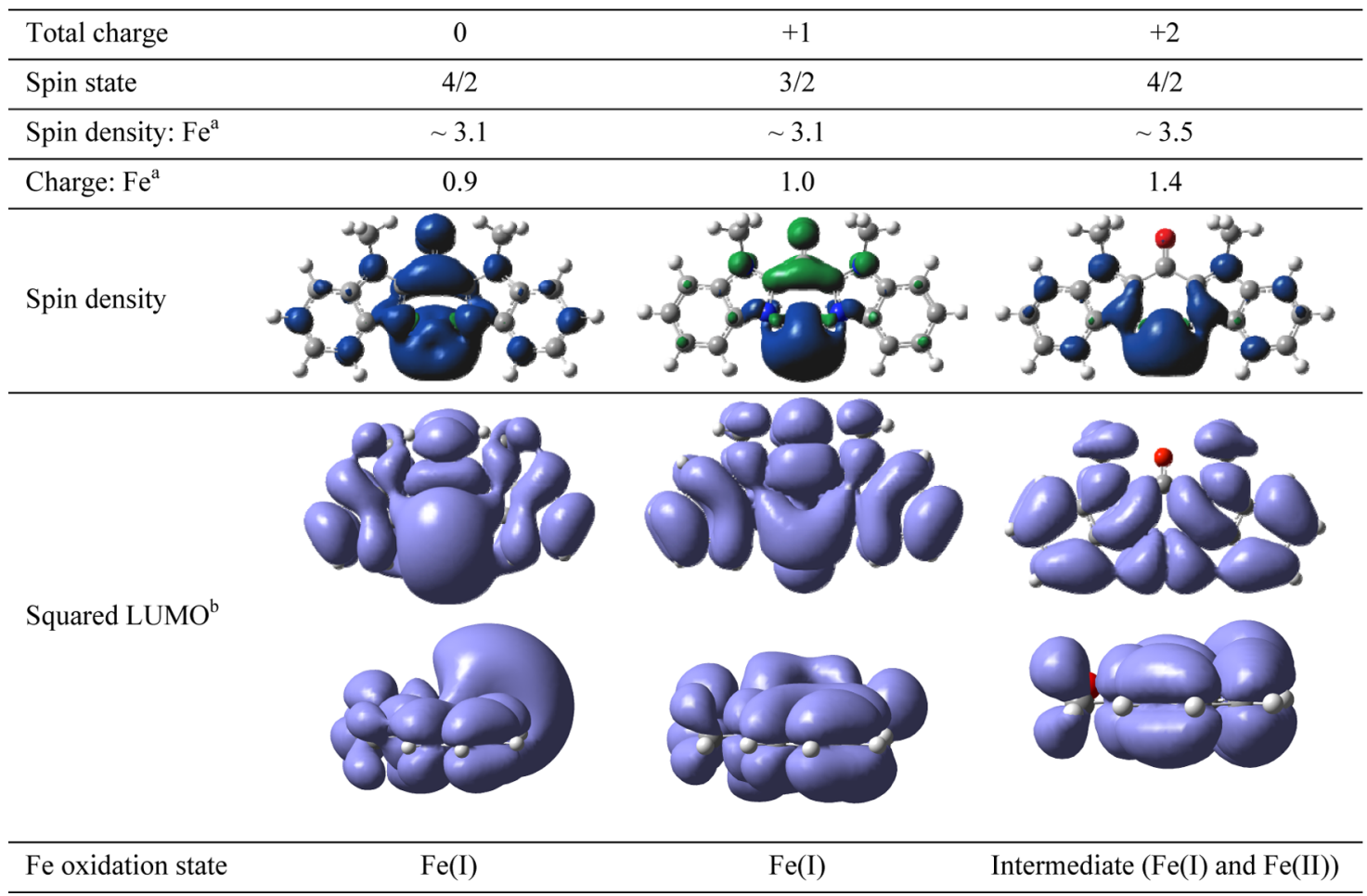

${ }^{a}$ The spin density and charges on iron were determined by NBO analysis. ${ }^{b}$ Only the $\beta$-LUMOs are shown, as they are significantly lower in energy compared to that of the $\alpha$-LUMOs. Calculations were done on the OPBZ/cc-pVTZ level of theory. ${ }^{58-60}$

with the Fermi level of the substrate and is not a priori known. The calculations were carried out on an isolated molecule, that is, the $\mathrm{Au}(111)$ surface was not included. The plausible total charges of the complex, $0,+1$, and +2 , were investigated in silico. All possible spin states, accessible by distributing the available d-electrons (depending on the total charge of the complex) over five nondegenerate $d$ orbitals and the LUMO of the ligand, were considered. For all charge states, the high-spin state yielded the lowest energy; they were found to be 3.8, 18.1, and $19.5 \mathrm{kcal} / \mathrm{mol}$ lower in energy than those of the intermediate spin states, for the $0,+1$, and +2 charge states, respectively. The intermediate spin states were again lower in energy than the low-spin states. This is similar to what has been found for the bulk complex $\left[\mathrm{Fe}(\mathrm{BMBIK}) \mathrm{Cl}_{2}\right]$ and what can be expected for such a low-coordinate iron complex. ${ }^{55,56}$ The resulting spin densities and probability density of the LUMO of the high-spin states are shown in Table 2. A natural bond orbital (NBO) analysis was used to compute the atomic charges and spin densities. The latter provide a basis for describing the electronic structure of the complex in terms of metal oxidation state and ligand noninnocence.

For the neutral complex, the quintet ground state was found to be in close proximity to the first triplet state $(3.8 \mathrm{kcal} / \mathrm{mol})$, and both states were well separated from the singlet $(27.3 \mathrm{kcal} /$ $\mathrm{mol}$ ). This situation is typical of redox noninnocence, in which one electron is transferred from the metal center to the ligand; ${ }^{20,57}$ weak ferromagnetic coupling between a high-spin $\mathrm{Fe}(\mathrm{I})$ center $(S=3 / 2)$ and a ligand-centered radical generates an $S=2$ ground state with a low lying $S=1$ excited state. The NBO spin density of 3.1 at the iron center and the spin density plot shown in Table 2 further validate the idea of a ligandcentered radical. The NBO charge on iron of 0.9 supports the idea that it is in the +1 oxidation state.
The complex with a total charge of +1 shows most of the spin density on the iron center (NBO spin density: 3.1 ) and only very little radical character on the ligand (NBO spin density on $\mathrm{C}=\mathrm{O}: 0.13$ ). This indicates a rather innocent behavior of the ligand in this charge state and an oxidation state of +1 of the iron center, as additionally supported by the NBO charge of 1.0.

Lastly, for the complex with a total charge of +2 , both the NBO charge and the spin density on iron do not yield an integer number (1.4 and 3.5, respectively). This suggests that the ground state is best described as a delocalized state in which the oxidation state of iron is intermediate between +1 and +2 , with partial oxidation of the ligand. Accordingly, the LUMO of the complex is a linear combination of a d orbital and a ligand $\pi$ orbital that is occupied in the unbound ligand (see Figure S7).

Besides the NBO spin densities and charges, Table 2 also shows the probability density of the LUMOs of the three charge states. Other unoccupied states are $>300 \mathrm{meV}$ higher in energy than the LUMO, showing that they are well separated. For the neutral complex, the LUMO is delocalized over the entire complex, with the largest amplitude above the Fe atom. The LUMO of the +1 complex is the same as that of the neutral species. However, the amplitude at the Fe atom is significantly reduced. In contrast, for the +2 state the LUMO is a different orbital. Note that this state has no $\pi^{*}(\mathrm{C}=\mathrm{O})$ character.

\section{DISCUSSION}

By comparing the probability densities of the LUMOs of different charge states with the experimental shape observed in the images acquired at a bias of $1.25 \mathrm{~V}$, the charge state and oxidation state of the iron center can be tentatively assigned. Upon comparing these probability densities of the LUMOs of the complexes with various charge states (Table 2) with the 
STM image recorded at $1.25 \mathrm{~V}$ and the plotted line profiles (Figure 5D,F), the charge state of +1 seems most plausible. The line profile shows the highest point close to the $\mathrm{CO}$ and a shoulder close to the iron center. The high intensity on $\mathrm{CO}$ makes the +2 charge state very unlikely, as the corresponding LUMO has no density on the CO unit. The LUMO calculated for the 0 charge has a stronger Fe character (see Table 2), whereas the LUMO of the +1 charged complex is evenly distributed over the molecule, in closer agreement with the experimental profile. In addition, the strong shift of the STS signal toward lower energies upon coordination supports the idea that a positively charged complex is formed. Hence, we favor the assignment of a +1 charge state, corresponding to a +1 oxidation state of the iron center. The observation of a charged molecule on a $\mathrm{Au}(111)$ surface has been reported before. $^{61}$

Overall, comparing the results obtained in solution and on a surface provides unique insights into the effect of metal coordination on the unoccupied electronic levels of the ligand, which both STS and CV probe. First, the energy of the LUMO of the free ligand appears to be rather insensitive to the microenvironment, as the reduction potentials on the surface and in solution are very similar (Figure 4, blue curves). This may appear surprising in view of the difference in microenvironment $(\mathrm{Au}(111)$ and vacuum versus glassy carbon and $\mathrm{MeCN}$ ) between the STS and CV experiments. The latter can be understood from the fact that the interaction between molecules and the $\mathrm{Au}(111)$ surface is typically very weak ${ }^{22,47}$ and is hence not expected to strongly impact the measurement. In the $\mathrm{CV}$ experiment, environmental effects are largely canceled out by referencing to the ferrocene/ferrocenium couple under the same conditions. Furthermore, differential solvation effects are typically small for large organic molecules with diffuse charge density, ${ }^{62}$ and their electrochemical reduction potentials have been shown to correlate well with resonant tunneling bands. ${ }^{30}$ Maybe more surprising is the fact that different species behave so similarly: the coordination to a charged $\mathrm{Fe}^{\mathrm{I}}$ ion on the surface imposes only a slightly larger shift $\left(\Delta E_{\mathrm{STS}}=1.0 \mathrm{~V}\right)$ than that from coordination to a neutral $\mathrm{Fe}^{\mathrm{II}} \mathrm{Cl}_{2}$ fragment in solution $\left(\Delta E_{\mathrm{CV}}=0.7 \mathrm{~V}\right)$. This suggests that the energy shift of the ligand $\pi$ orbitals upon binding mostly stems from the ensuing orbital interactions (Lewis acid/base complex formation) and is only moderately sensitive to the oxidation state of the metal or to the surrounding ligand. From the slightly larger shift observed by STS, it appears that the overall charge of the complex has a stronger influence on the ligand $\pi$ orbitals than the formal oxidation state of the metal.

\section{CONCLUSIONS}

To conclude, the BMBIK ligand has been successfully coordinated to an iron center both in solution and on a $\mathrm{Au}(111)$ surface. $\left[\mathrm{Fe}^{\mathrm{II}}(\mathrm{BMBIK}) \mathrm{Cl}_{2}\right]$ synthesized in the bulk phase has been structurally characterized using X-ray crystal structure determination, which shows that the ligand stays flat upon coordination to the iron center. $\left[\mathrm{Fe}^{\mathrm{I}}(\mathrm{BMBIK})\right]^{+}$was synthesized on the single molecule level using lateral manipulation in STM. Even though the molecular shape of $\left[\mathrm{Fe}^{\mathrm{I}}(\mathrm{BMBIK})\right]^{+}$is similar to free BMBIK, they could be distinguished using STS, as the energy of the LUMO shifts downward $(\Delta 1.0 \mathrm{~V})$ upon coordination to the iron center. By comparing the STS results at the single molecule level to the $\mathrm{CV}$ measurements on the bulk phase it was found that the shift in LUMO energy is similar in both systems. On the basis of
DFT studies, it is tentatively proposed that on the $\mathrm{Au}(111)$ surface, the iron center in $[\mathrm{Fe}(\mathrm{BMBIK})]^{+}$is in the +1 oxidation state and adopts the high-spin state with only minor spin density on the ligand.

The synthesis of $\left[\mathrm{Fe}^{\mathrm{I}}(\mathrm{BMBIK})\right]^{+}$via lateral manipulation provides a first step in the single molecule study of catalytic cycles that involve NIL metal complexes. Such studies will of course need to take into account the marked difference between the conditions found in the SPM/STM conditions (UHV, cryogenic temperatures) and those of a "real life" catalytic transformation (condensed phase, higher temperatures). In this respect, the correlation between CV and STS data demonstrate a reassuring similarity between the solution and surface compounds. In addition, the UHV/cryogenic environment provides the opportunity to synthesize and study species that would be too short-lived to be characterized in the condensed phase, such as the low-coordinate iron complex $\left[\mathrm{Fe}^{\mathrm{I}}(\mathrm{BMBIK})\right]^{+}$that is similar to proposed reactive intermediates in catalytic cycles. ${ }^{8,20}$ In the future, X-ray photoelectron spectroscopy experiments could allow us to experimentally determine the oxidation state of the iron center. $^{26,27,29}$ This opens up new routes toward the study of catalytic cycles using redox active NIL metal complexes.

\section{EXPERIMENTAL SECTION}

All air-sensitive organic reactions, as well as the handling and synthesis of iron complexes, were carried out under an inert atmosphere of dry and oxygen-free $\mathrm{N}_{2}$ using standard Schlenk techniques, or were handled in an MBraun labmaster dp glovebox workstation. Dry $\mathrm{MeCN}$ and toluene were obtained from an MBraun MB SPS- 800 solvent purification system. THF was distilled over sodium/benzophenone under $\mathrm{N}_{2}$ before use. All dry solvents were degassed by bubbling $\mathrm{N}_{2}$ through the liquid for ca. $30 \mathrm{~min}$ or by freeze-pump-thaw cycles prior to use and stored over 3 or $4 \AA$ molecular sieves. $\mathrm{CD}_{2} \mathrm{Cl}_{2}$ was degassed by freeze-pump-thaw cycles prior to use and stored over $4 \AA$ molecular sieves. The ${ }^{1} \mathrm{H}$ NMR spectra were recorded at $298 \mathrm{~K}$ on a Varian VNMRS400 or an Oxford NMR AS400 spectrometer at $400 \mathrm{MHz}$. Chemical shifts $(\delta)$ are reported in ppm and referenced against residual solvent signal. Attenuated total reflection (ATR) infrared spectra were recorded on a Perkin-Elmer Spectrum One FT-IR spectrometer. The UV-vis spectra were recorded on an Agilent Cary 50 UV-vis spectrometer; wavelengths are reported in nanometers. The ESIMS spectra were recorded on a Waters LCT Premier XE KE317 Micromass Technologies spectrometer. CV measurements were performed on a Princeton 263A potentiostat/ galvanostat, using a $\mathrm{Pt}$ counter electrode, a glassy carbon working electrode, and a $\mathrm{Ag} / \mathrm{AgNO}_{3}$ reference electrode. All data are referenced to ferrocene. Analyte concentrations were typically between 0.5 and $5 \mathrm{mM}$ in a $0.1 \mathrm{M} \mathrm{NBu}_{4} \mathrm{PF}_{6}$ in $\mathrm{MeCN}$ electrolyte. Elemental microanalysis was carried out by the Mikroanalytischen Laboratorium Kolbe, Mulheim a.d. Ruhr, Germany. BMBIK was synthesized in accordance with the literature procedure. ${ }^{44}$ All other chemicals were commercially obtained and used as received. The clean $\mathrm{Au}(111)$ surface was prepared using several Argon sputter/anneal cycles. All STM/ AFM experiments were performed on an LT-STM/AFM (Scienta Omicron $\mathrm{GmbH}$ ) kept at $4.5 \mathrm{~K}$ in a vacuum chamber with a base pressure $<1 \times 10^{-9}$ mbar. Molecules were evaporated directly onto the cold surface from a stainless steel crucible in an EFM3 e-beam evaporator (Focus $\mathrm{GmbH}$ ). $\mathrm{Fe}$ atoms were obtained on the surface from the same e-beam 
evaporator using an Fe-rod (99.999\%, Mateck $\mathrm{GmbH}$ ) as a source. The manipulation of the BMBIK molecule was achieved by lowering the tip-sample distance approximately $5 \AA$ after disconnecting the feedback loop and setting the bias to $0 \mathrm{~V}$. A stroke at constant height over the molecule resulted in the relocation of the molecule in the direction of movement. STS spectra were recorded using a lockin amplifier $\left(f_{\bmod }=273 \mathrm{~Hz}\right.$, $\left.V_{\text {mod }}=10 \mathrm{mV}(\mathrm{rms})\right)$.

[Fe(BMBIK)Cl$)_{2}$ ]. To a solution of $\mathrm{FeCl}_{2} \cdot 1.5 \mathrm{THF}(35 \mathrm{mg}$, $0.15 \mathrm{mmol})$ in THF $(2.5 \mathrm{~mL})$ was added a suspension of BMBIK (44 mg, $0.15 \mathrm{mmol}$ ) in THF $(1.5 \mathrm{~mL})$ resulting in a color change from white to green. The solution was left stirring overnight, after which it was filtered, and the residue was collected and dried in vacuo. The product was obtained as a green solid (51 mg, 82\%). Crystals suitable for X-ray crystal structure determination were obtained from a concentrated $\mathrm{MeCN}$ solution by slow evaporation of $\mathrm{MeCN}$ into toluene in the surrounding vial. Anal. for $\mathrm{C}_{17} \mathrm{H}_{14} \mathrm{Cl}_{2} \mathrm{FeN}_{4} \mathrm{O}$ (417.07), calc. C, 48.96; H, 3.38; N, 13.43; found C, 49.04; H, 3.24; N, 13.33. ${ }^{1} \mathrm{H}$ NMR (400 MHz, $\left.\mathrm{CD}_{2} \mathrm{Cl}_{2}, 25{ }^{\circ} \mathrm{C}\right): \delta=-40\left(\mathrm{br}, 2 \mathrm{H}, \mathrm{H}_{\mathrm{Bim}}\right)$, $-11.26\left(2 \mathrm{H}, H_{\text {Bim }}\right), 5.42\left(2 \mathrm{H}, H_{\text {Bim }}\right), 16.64\left(2 \mathrm{H}, H_{\text {Bim }}\right), 40.40$ $\left(6 \mathrm{H}, \mathrm{NCH}_{3}\right)$ ppm. IR (ATR): $\nu=3088.6,3057.3,3023.4$, 2960.9, 1657.0, 1589.4, 1497.4, 1477.2, 1454.5, 1432.9, 1394.8, 1342.3, 1289.7, 1218.6, 1127.7, 1104.1, 970.68, 914.57, 833.96, 748.6, 590.7, 554.18, $528.9 \mathrm{~cm}^{-1}$. ESIMS $\left(\mathrm{CH}_{2} \mathrm{Cl}_{2}\right): \mathrm{m} / z=$ $291.0970\left\{\left[\mathrm{BMBIK}+\mathrm{H}^{+}\right]\right.$, calc. 291.1246$\}, 381.0139\{[\mathrm{Fe}-$ (BMBIK)Cl $]^{+}$, calc. 381.0206$\}, 422.0439\{[\mathrm{Fe}(\mathrm{BMBIK}) \mathrm{Cl}+$ $\mathrm{MeCN}]^{+}$, calc. 422.0472$\}, 439.0534\left\{\left[\mathrm{Fe}(\mathrm{BMBIK}) \mathrm{Cl}_{2}+\mathrm{Na}\right]^{+}\right.$, calc. 438.9793$\}, 671.1212\left\{\left[\mathrm{Fe}(\mathrm{BMBIK})_{2} \mathrm{Cl}\right]^{+}\right.$, calc. 671.1374$\}$. $\mathrm{UV}-$ vis $(\mathrm{MeCN}): \lambda_{\max }=575 \mathrm{~nm}$.

X-ray Crystal Structure Determination. $\mathrm{C}_{17} \mathrm{H}_{14} \mathrm{Cl}_{2} \mathrm{FeN}_{4} \mathrm{O}, \mathrm{fw}=417.07$, brown needle, $0.77 \times 0.21 \times$ $0.08 \mathrm{~mm}^{3}$, triclinic, $P_{\overline{1}}$ (no. 2), $a=9.1214(3), b=11.7012(4), c$ $=16.1591(5) \AA, \alpha=83.738(2), \beta=89.466(1), \gamma=87.936(2)^{\circ}$, $V=1713.27(10) \AA^{3}, Z=4, D_{x}=1.617 \mathrm{~g} / \mathrm{cm}^{3}, \mu=1.21 \mathrm{~mm}^{-1}$. A total of 29927 reflections were measured on a Bruker Kappa ApexII diffractometer with a sealed tube and Triumph monochromator $(\lambda=0.71073 \AA)$ at a temperature of $150(2)$ $\mathrm{K}$ up to a resolution of $(\sin \theta / \lambda)_{\max }=0.65 \AA^{-1}$. The Eval15 software $^{63}$ was used for the integration of the intensities. A numerical absorption correction and scaling was performed with $\mathrm{SADABS}^{64}$ (correction range 0.56-0.92). A total of 7857 reflections were unique $\left(R_{\mathrm{int}}=0.016\right)$, of which 7154 were observed $[I>2 \sigma(I)]$. The structure was solved with Patterson superposition methods using SHELXT. ${ }^{65}$ Least-squares refinement was performed with SHELXL-2014 ${ }^{66}$ against $F^{2}$ for all reflections. Nonhydrogen atoms were refined freely with anisotropic displacement parameters. All hydrogen atoms were located in difference Fourier maps and refined with a riding model. A total of 455 parameters were refined with no restraints. $R 1 / \mathrm{w} R 2[I>2 \sigma(I)]: 0.0219 / 0.0556 . R 1 / \mathrm{wR} 2$ [all refl.]: $0.0252 / 0.0572 . S=1.030$. Residual electron density was between -0.24 and $0.34 \mathrm{e} / \AA^{3}$. Geometry calculations and checking for higher symmetry were performed with the PLATON program. ${ }^{67}$

Computational Details. DFT results were obtained using the Gaussian 09 software package, ${ }^{68}$ using the OPBZ functional and the cc-pVTZ basis set. This level of theory was chosen as it has been shown that it leads to a correct prediction of the correct spin ground state of $\mathrm{Fe}$ complexes. ${ }^{58-60}$ Frequency analyses were performed on all calculations. DFT calculationderived pictures were generated using the GaussView 5.0.8. software, the NBO6 program up to the NLMO basis set was used. $^{69}$

\section{ASSOCIATED CONTENT}

\section{Supporting Information}

The Supporting Information is available free of charge on the ACS Publications website at DOI: 10.1021/acsomega.6b00510. ESIMS, NMR, IR, and DFT data (PDF) $\mathrm{X}$-ray crystal structure determination data (CIF)

\section{AUTHOR INFORMATION}

\section{Corresponding Authors}

*E-mail: I.Swart@uu.nl (I.S.).

*E-mail: M.Moret@uu.nl (M.-E.M.).

ORCID

Marc-Etienne Moret: 0000-0002-3137-6073

\section{Author Contributions}

The manuscript was written through contributions of all authors. All authors have given approval to the final version of the manuscript.

\section{Notes}

The authors declare no competing financial interest.

\section{ACKNOWLEDGMENTS}

The authors would like to thank the Dutch National Research School Combination-Catalysis Controlled by Chemical Design (NRSC-Catalysis) for their financial support. M.-E.M. acknowledges funding from the European Union Seventh Framework Programme (FP7/2007-2013) under grant agreement PIIF-GA- 2012-327306 (IIF-Marie Curie grant) and Utrecht University (Tenure-track grant, Sectorplan Natuur- en Scheikunde). The DFT work was carried out on the Dutch national e-infrastructure with the support of the SURF Foundation. The X-ray diffractometer was financed by the Netherlands Organization for Scientific Research (NWO). We thank L. Witteman for assistance with an NMR experiment.

\section{REFERENCES}

(1) Blanchard, S.; Derat, E.; Desage-El Murr, M.; Fensterbank, L.; Malacria, M.; Mouriès-Mansuy, V. Eur. J. Inorg. Chem. 2012, 2012, 376-389.

(2) van der Vlugt, J. I. Eur. J. Inorg. Chem. 2012, 2012, 363-375.

(3) Khusnutdinova, J. R.; Milstein, D. Angew. Chem., Int. Ed. 2015, 54, 12236-12273.

(4) Kaim, W.; Schwederski, B. Coord. Chem. Rev. 2010, 254, 15801588.

(5) Luca, O. R.; Crabtree, R. H. Chem. Soc. Rev. 2013, 42, 14401459.

(6) Lyaskovskyy, V.; de Bruin, B. ACS Catal. 2012, 2, 270-279.

(7) Chirik, P. J.; Wieghardt, K. Science 2010, 327, 794-795.

(8) Bart, S. C.; Lobkovsky, E.; Chirik, P. J. J. Am. Chem. Soc. 2004, 126, 13794-13807.

(9) Dzik, W. I.; van der Vlugt, J. I.; Reek, J. N. H.; de Bruin, B. Angew. Chem., Int. Ed. 2011, 50, 3356-3358.

(10) King, E. R.; Hennessy, E. T.; Betley, T. A. J. Am. Chem. Soc. 2011, 133, 4917-4923.

(11) Cheng, C.; Hartwig, J. F. Chem. Rev. 2015, 115, 8946-8975.

(12) Hoyt, J. M.; Schmidt, V. A.; Tondreau, A. M.; Chirik, P. J. Science 2015, 349, 960-963.

(13) Lagaditis, P. O.; Sues, P. E.; Sonnenberg, J. F.; Wan, K. Y.; Lough, A. J.; Morris, R. H. J. Am. Chem. Soc. 2014, 136, 1367-1380.

(14) Bart, S. C.; Bowman, A. C.; Lobkovsky, E.; Chirik, P. J. J. Am. Chem. Soc. 2007, 129, 7212-7213. 
(15) Blackmore, K. J.; Lal, N.; Ziller, J. W.; Heyduk, A. F. J. Am. Chem. Soc. 2008, 130, 2728-2729.

(16) Nguyen, A. I.; Zarkesh, R. A.; Lacy, D. C.; Thorson, M. K.; Heyduk, A. F. Chem. Sci. 2011, 2, 166-169.

(17) Heyduk, A. F.; Zarkesh, R. A.; Nguyen, A. I. Inorg. Chem. 2011, 50, 9849-9863.

(18) Chang, M. C.; Dann, T.; Day, D. P.; Lutz, M.; Wildgoose, G. G.; Otten, E. Angew. Chem., Int. Ed. 2014, 53, 4118-4122.

(19) Brown, S. N. Inorg. Chem. 2012, 51, 1251-1260.

(20) Bart, S. C.; Chłopek, K.; Bill, E.; Bouwkamp, M. W.; Lobkovsky, E.; Neese, F.; Wieghardt, K.; Chirik, P. J. J. Am. Chem. Soc. 2006, 128, 13901-13912.

(21) Repp, J.; Meyer, G.; Stojković, S. M.; Gourdon, A.; Joachim, C. Phys. Rev. Lett. 2005, 94, No. 026803.

(22) Soe, W. H.; Manzano, C.; Sarkar, A.; De, Chandrasekhar, N.; Joachim, C. Phys. Rev. Lett. 2009, 102, No. 176102.

(23) Urgel, J. I.; Ecija, D.; Auwärter, W.; Barth, J. V. Nano Lett. 2014, $14,1369-1373$.

(24) Choi, T.; Badal, M.; Loth, S.; Yoo, J.-W.; Lutz, C. P.; Heinrich, A. J.; Epstein, A. J.; Stroud, D. G.; Gupta, J. A. Nano Lett. 2014, 14, $1196-1201$.

(25) Albrecht, F.; Neu, M.; Quest, C.; Swart, I.; Repp, J. J. Am. Chem. Soc. 2013, 135, 9200-9203.

(26) Weber, P. B.; Hellwig, R.; Paintner, T.; Lattelais, M.; Paszkiewicz, M.; Casado Aguilar, P.; Deimel, P. S.; Guo, Y.; Zhang, Y.-Q.; Allegretti, F.; Papageorgiou, A. C.; Reichert, J.; Klyatskaya, S.; Ruben, M.; Barth, J. V.; Bocquet, M.-L.; Klappenberger, F. Angew. Chem. Int. Ed. 2016, 55, 5754-5759.

(27) Seo, S.; Lee, J.; Choi, S.-Y.; Lee, H. J. Mater. Chem. 2012, 22, $1868-1875$.

(28) Zhang, C.; Sun, Q.; Kong, H.; Wang, L.; Tan, Q.; Xu, W. Chem. Commun. 2014, 50, 15924-15927.

(29) Skomski, D.; Tempas, C. D.; Cook, B. J.; Polezhaev, A. V.; Smith, K. A.; Caulton, K. G.; Tait, S. L. J. Am. Chem. Soc. 2015, 137, 7898-7902.

(30) Mazur, U.; Hipps, K. W. J. Phys. Chem. 1995, 99, 6684-6688.

(31) Salvatore, P.; Glargaard Hansen, A.; Moth-Poulsen, K.; Bjørnholm, T.; John Nichols, R.; Ulstrup, J. Phys. Chem. Chem. Phys. 2011, 13, 14394.

(32) Kong, X.-H.; Wang, M.; Lei, S.-B.; Yang, Y.-L.; Wang, C. J. Mater. Chem. 2006, 16, 4265.

(33) Hendriksen, B. L. M.; Frenken, J. W. M. Phys. Rev. Lett. 2002, 89, No. 046101.

(34) Leibsle, F. M.; Murray, P. W.; Francis, S. M.; Thornton, G.; Bowker, M. Nature 1993, 363, 706-709.

(35) Ertl, G. Angew. Chem. 2008, 120, 3578-3590.

(36) Tao, F. F.; Crozier, P. A. Chem. Rev. 2016, 116, 3487-3539.

(37) Navarro, V.; van Spronsen, M. A.; Frenken, J. W. M. Nat. Chem.

2016, 8, 929-934.

(38) Freund, H.-J. J. Am. Chem. Soc. 2016, 138, 8985-8996.

(39) Vang, R. T.; Lauritsen, J. V.; Laegsgaard, E.; Besenbacher, F. Chem. Soc. Rev. 2008, 37, 2191-2203.

(40) Setvin, M.; Aschauer, U.; Hulva, J.; Simschitz, T.; Daniel, B.; Schmid, M.; Selloni, A.; Diebold, U. J. Am. Chem. Soc. 2016, 138, 9565-9571.

(41) Hulsken, B.; van Hameren, R; Gerritsen, J. W.; Khoury, T.; Thordarson, P.; Crossley, M. J.; Rowan, A. E.; Nolte, R. J. M.; Elemans, J. A. A. W.; Speller, S. Nat. Nanotechnol. 2007, 2, 285-289.

(42) Folkertsma, E.; Benthem, S. H.; Witteman, L.; van Slagmaat, C. A. M. R.; Lutz, M.; Klein Gebbink, R. J. M.; Moret, M.-E. Submitted for publication.

(43) Pavliček, N.; Schuler, B.; Collazos, S.; Moll, N.; Pérez, D.; Guitián, E.; Meyer, G.; Peña, D.; Gross, L. Nat. Chem. 2015, 7, 623628.

(44) Elgafi, S.; Field, L. D.; Messerle, B. A.; Turner, P.; Hambley, T. W. J. Organomet. Chem. 1999, 588, 69-77.

(45) Bénisvy, L.; Chottard, J.-C.; Marrot, J.; Li, Y. Eur. J. Inorg. Chem. 2005, 999-1002.
(46) Jové, F. A.; Pariya, C.; Scoblete, M.; Yap, G.; Theopold, K. H. Chem. Eur. J. 2011, 17, 1310-1318.

(47) van der Lit, J.; Boneschanscher, M. P.; Vanmaekelbergh, D.; Ijäs, M.; Uppstu, A.; Ervasti, M.; Harju, A.; Liljeroth, P.; Swart, I. Nat. Commun. 2013, 4, No. 2023.

(48) Gross, L.; Mohn, F.; Moll, N.; Liljeroth, P.; Meyer, G. Science 2009, 325, 1110-1114.

(49) Hapala, P.; Kichin, G.; Wagner, C.; Tautz, F. S.; Temirov, R.; Jelínek, P. Phys. Rev. B 2014, 90, No. 085421.

(50) Hämäläinen, S. K.; van der Heijden, N.; van der Lit, J.; den Hartog, S.; Liljeroth, P.; Swart, I. Phys. Rev. Lett. 2014, 113, No. 186102.

(51) Pavliček, N.; Fleury, B.; Neu, M.; Niedenfuhr, J.; HerranzLancho, C.; Ruben, M.; Repp, J. Phys. Rev. Lett. 2012, 108, No. 086101.

(52) Liljeroth, P.; Swart, I.; Paavilainen, S.; Repp, J.; Meyer, G. Nano Lett. 2010, 10, 2475-2479.

(53) Yang, Z.; Corso, M.; Robles, R.; Lotze, C.; Fitzner, R.; MenaOsteritz, E.; Bäuerle, P.; Franke, K. J.; Pascual, J. I. ACS Nano 2014, 8, 10715-10722.

(54) Repp, J.; Meyer, G.; Paavilainen, S.; Olsson, F. E.; Persson, M. Phys. Rev. Lett. 2005, 95, No. 225503.

(55) Power, P. P. Chem. Rev. 2012, 112, 3482-3507.

(56) Holland, P. L. Angew. Chem., Int. Ed. 2011, 50, 6213-6214.

(57) Dugan, T. R.; Bill, E.; MacLeod, K. C.; Christian, G. J.; Cowley, R. E.; Brennessel, W. W.; Ye, S.; Neese, F.; Holland, P. L. J. Am. Chem. Soc. 2012, 134, 20352-20364.

(58) Daul, C.; Zlatar, M.; Gruden-Pavlović, M.; Swart, M. In Spin States in Biochemistry and Inorganic Chemistry; John Wiley \& Sons, Ltd: Oxford, U.K., 2015; pp 7-34.

(59) Swart, M. J. Chem. Theory Comput. 2008, 4, 2057-2066.

(60) Gruden, M.; Stepanovic, S.; Swart, M. J. Serb. Chem. Soc. 2015, 80, 1399-1410.

(61) Heimel, G.; Duhm, S.; Salzmann, I.; Gerlach, A.; Strozecka, A.; Niederhausen, J.; Bürker, C.; Hosokai, T.; Fernandez-Torrente, I.; Schulze, G.; Winkler, S.; Wilke, A.; Schlesinger, R.; Frisch, J.; Bröker, B.; Vollmer, A.; Detlefs, B.; Pflaum, J.; Kera, S.; Franke, K. J.; Ueno, N.; Pascual, J. I.; Schreiber, F.; Koch, N. Nat. Chem. 2013, 5, 187-194.

(62) Connelly, N. G.; Geiger, W. E. Chem. Rev. 1996, 96, 877-910.

(63) Schreurs, A. M. M.; Xian, X.; Kroon-Batenburg, L. M. J. J. Appl. Crystallogr. 2010, 43, 70-82.

(64) Sheldrick, G. M. SADABS; University of Göttingen: Germany, 2008.

(65) Sheldrick, G. M. Acta Crystallogr., Sect. A: Found. Adv. 2015, 71, $3-8$.

(66) Sheldrick, G. M. Acta Crystallogr., Sect. C: Struct. Chem. 2015, 71, $3-8$.

(67) Spek, A. L. Acta Crystallogr., Sect. D: Struct. Biol. 2009, 65, 148155.

(68) Frisch, M. J.; Trucks, G. W.; Schlegel, H. B.; Scuseria, G. E.; Robb, M. A.; Cheeseman, J. R.; Scalmani, G.; Barone, V.; Mennucci, B.; Petersson, G. A.; Nakatsuji, H.; Caricato, M.; Li, X.; Hratchian, H. P.; Izmaylov, A. F.; Bloino, J.; Zheng, G.; Sonnenberg, J. L.; Hada, M.; Ehara, M.; Toyota, K.; Fukuda, R.; Hasegawa, J.; Ishida, M.; Nakajima, T.; Honda, Y.; Kitao, O.; Nakai, H.; Vreven, T.; Montgomery, J. A., Jr.; Peralta, J. E.; Ogliaro, F.; Bearpark, M.; Heyd, J. J.; Brothers, E.; Kudin, K. N.; Staroverov, V. N.; Keith, T.; Kobayashi, R.; Normand, J.; Raghavachari, K.; Rendell, A.; Burant, J. C.; Iyengar, S. S.; Tomasi, J.; Cossi, M.; Rega, N.; Millam, J. M.; Klene, M.; Knox, J. E.; Cross, J. B.; Bakken, V.; Adamo, C.; Jaramillo, J.; Gomperts, R.; Stratmann, R. E.; Yazyev, O.; Austin, A. J.; Cammi, R.; Pomelli, C.; Ochterski, J. W.; Martin, R. L.; Morokuma, K.; Zakrzewski, V. G.; Voth, G. A.; Salvador, P.; Dannenberg, J. J.; Dapprich, S.; Daniels, A. D.; Farkas, O.; Foresman, J. B.; Ortiz, J. V.; Cioslowski, J.; Fox, D. J. Gaussian 09, revision D.01; Gaussian, Inc.: Wallingford, CT, 2013.

(69) Glendening, E. D.; Badenhoop, J. K.; Reed, A. E.; Carpenter, J. E.; Bohmann, J. A.; Morales, C. M.; Landis, C. R; Weinhold, F. NBO, version 6.0; Theoretical Chemistry Institute, University of Wisconsin: Madison, WI, 2013. http://nbo6.chem.wisc.edu/. 